Biorheology, Vol. 26, pp. I-III, 1989

$0006-355 X / 89 \$ 3.00+.00$ Printed in the USA

Copyright (c) 1989 Pergamon Press plc. All rights reserved.

\title{
EDITORIAL: \\ SOFTWARE SURVEY SECTION
}

The purpose of the Software Survey Section in BIORHEOLOGY is to encourage the open exchange of information on software programs unique to our professional field. With the rapid penetration of computers into academic and industrial institutions has come a parallel increase in the number of scientists and researchers designing their own software. The existence of much of this software remains unknown to even those of us who could most benefit from its use. We believe that it is of vital importance to our readers that such information be made available. We believe also that a professional journal is the best place to share such information. Your contribution would be most welcome.

The questionnaire on the following pages is designed to assist you in reporting on software that you may have developed or be in the process of developing. By completing this form, your information will reach thousands of your colleagues who may benefit from your work and may possibly offer suggestions for further enhancements to your software. Please complete the enclosed form and return it to:

Dr. Andrew D. McCulloch

Department of Applied Mechanics and Engineering Sciences

Bioengineering, R-012

University of California/San Diego

La Jol1a, CA 92093-0412

We do not intend to review or comment on the contents of the questionnaire. It will be published as is in order to expedite the information cycle process. I would welcome any comments you may have. 
NAME OF JOURNAL BIORHEOLOGY

PERGAMON PRES S

SOFTWARE DESCRIPTION FORM

Title of software program:

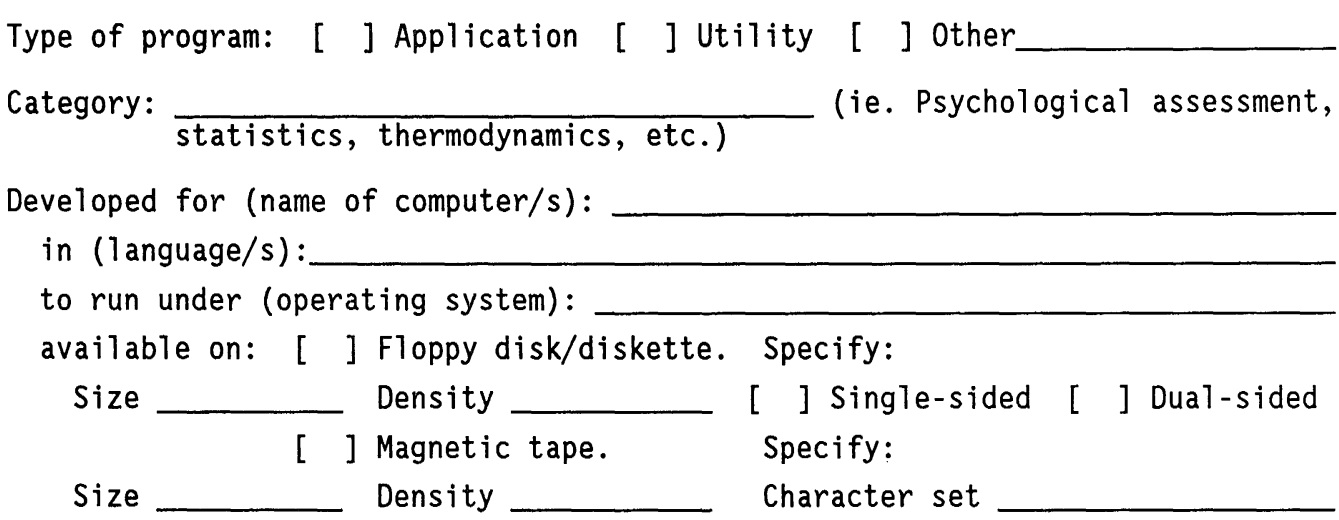

Hardware required:

Memory required:

User training required: [ ] Yes [ ] No

Documentation: [ ] None [ ] Minimal [ ] Self-documenting

[ ]Extensive external documentation

Source code available: [ ] Yes [ ] No

Stage of development: [ ] Design complete [ ] Coding complete [ ] Fully operational [ ] Collaboration welcomed

Is program in use? [ ] Yes How long?___ How many sites?

Is the contributor available for user inquiries: [ ] Yes [ ] No

Distributed by:

Cost of program:

Demonstration disk available? [ $]$ Y Yes Cost:

RETURN COMPLETED FORM TO:

(continued)

Dr. Andrew D. McCulloch

Department of Applied Mechanics and Engineering Sciences

Bioengineering, R-012

University of Cal ifornia/San Diego

La Jo11a, CA 92093-0412

[This Software Description Form may be photocopied without permission] 
Description of what software does [200 words]:

Potential users:

Fields of interest:

Name of contributor:

Institution:

Address:

Telephone number:

\section{\#\#\#\#\#\#\#}

Reference No. [Assigned by Journal Editor]

[The information below is not for publication.]

Would you like to have your program:

Reviewed? $[$ YYes [] No $[$ Not at this time

Marketed and distributed? $[$ JYes $[$ No $[$ Not at this time

[This Software Description Form may be photocopied without permission] 